\title{
Improvement of Surface Quality and Machining Depth of $\mu$-ECDM Performances Using Mixed Electrolyte at Different Polarity
}

\section{BIJAN MALLICK ( $\sim$ BIJAN.JU@GMAIL.COM )}

Global Institute of Management and Technology https://orcid.org/0000-0003-1483-5861

\section{B R SARKAR}

Jadavpur University

B DOLOI

Jadavpur University

\section{B BHATTACHARYYA}

Jadavpur University

\section{Research Article}

Keywords: $\mu$-ECDM, Machining depth, Surface roughness (Ra), TEWR, 'Zig-Zag', 'Y'shaped, Micro-slot, Mixed electrolyte, Polarity

Posted Date: September 2nd, 2021

DOl: https://doi.org/10.21203/rs.3.rs-854051/v1

License: (9) This work is licensed under a Creative Commons Attribution 4.0 International License. Read Full License

Version of Record: A version of this preprint was published at Silicon on January 9th, 2022. See the published version at https://doi.org/10.1007/s12633-021-01587-2. 


\section{Abstract}

The production of miniature parts and various shape of micro-profile by electrochemical discharge micromachining process $(\mu-E C D M)$ draw challenging attention to the researchers. Parametric influences as well as comparative analysis on machining depth $(M D)$ and surface roughness $\left(R_{a}\right)$ has been propounded using $\mathrm{NaOH}$ and $\mathrm{KOH}$ at the ratio of 1:0, 3:1, 1:1, 1:3 and 0:1 with their varying concentration(wt.\%), and applied voltage $(\mathrm{V})$, pulse frequency $(\mathrm{Hz})$ and duty ratio (\%)in straight as well as in reverse polarity using template guided stainless steel (SS) cylindrical tool with motion and spring feed mechanism for fabrication of different shapes of micro-channel like Zig-Zag, ' $Y$ ' shaped on glass by $\mu$-ECDM process. Tool electrode wear rate (TEWR) has been reduced using mixed electrolyte and reversed polarity. The SEM analysis has been performed to identify the micro-crack and uncut debris into micro-channel. Machining depth has been increased up to $1850 \mu \mathrm{m}$ with better surface quality using mixed electrolyte of $\mathrm{NaOH}: \mathrm{KOH}:: 3: 1$ at direct polarity of $50 \mathrm{~V}$ and lower TEWR is found using $\mathrm{NaOH}: \mathrm{KOH}:: 1: 3$ as electrolyte at reverse polarity.

\section{Introduction}

Complex profile and micro-channel generation with higher machining depth is an exigent issue to the researchers by $\mu$-ECDM process. Basak and Ghosh, [1] and also Bhattacharyya et al. [2] illustrated the spark generation as well as material removal mechanism of ECDM process. Wuthrich and Fascio[3] propounded that the surface texture of the job specimen was exaggerated by applied voltage and electrolyte conductivity. Sarkar et al. [4] analysed the parametric influences on machining criteria like MRR, HAZ and OC during micro-drilling on advanced ceramics. Kim et al. [5] experimentally proved that the surface roughness (SR) amplified if duty ratio is increased but opposite action of pulse frequency appeared during micro-drilling by ECDM. Yan et al. [6] used EPD-grinding to improve surface roughness of micro holes. Sarkar et al. [7] fabricated micro-holes on advanced ceramics by micro-ECDM process and showed that the quality of machining criteria influenced by applied voltage and electrolyte concentration. Sarkar et al. [8] first designed power circuit for ECDM for micro-drilling on ceramics. Han et al. [9] used an ultrasonic-vibrated electrolyte for improvement the geometric configuration of electrochemical discharge micro-drilling performances. Cheng et al. [10] utilized the magnetic field-assisted electrochemical discharge machining for improvement the machining efficiency and accuracy of ECDM process. Liu et al. [11] obtained the machining depth up to $150 \mu \mathrm{m}$ during ECDM performances. Yang et al. [12] concluded that the least tool wear rate (TWR) found for tungsten carbide (WC). Cheng et al. [13] produced of micro-holes on brittle materials. Cao et al. [14] did the experimentation by ECDM and micro-grinding using polycrystalline diamond (PCD) tools to improve the surface quality. Gupta et al. [15] illustrated that the pulse duration affected on aspect ratio of job specimen during ECDM process. Hajian et al. [16] used magnetic field to increase machining depth during the ECDM process. Saranya et al. [17] used a dynamic cylindrical tool electrode for improvement performance characteristics of ECDM process. Behroozfar et al. [18] showed that tool surface temperature at high voltage caused higher tool wear rate. Mallick et al. [19] illustrated parametric effects on machining criteria using GA. Madhavi et al. [20] fabricated micro- 
channel on quartz of $4 \mathrm{~mm}$ thickness. Bellubbi et.al.[21] optimized micro-machining performances of ECDM process using GRA technique.

Hence, from the literature survey it is clear that different researchers and scientist have carried out performances to fulfil their target but a vital attention can be drawn out to fabricate different shape of micro-channel on silica glass by ECDM process. This paper includes the development of an indigenously advanced $\mu$-ECDM system which consists automated spring feeding arrangement with cam-follower based tool guided unit for generation of different shapes of micro-channel like Zig-Zag, ' $Y$ ' shaped and micro-slot on glass for utilization as micro-fluidic device. The paper search out the basic experimental investigations of parametric influences as well as comparative analysis of different process parameters for Machining Depth (MD) and Surface Roughness $\left(R_{a}\right)$ using various mixed electrolyte of different weight proportion like $\mathrm{NaOH}: \mathrm{KOH}:: 1: 0, \mathrm{NaOH}: \mathrm{KOH}:: 0: 1, \mathrm{NaOH}: \mathrm{KOH}:: 1: 1, \mathrm{NaOH}: \mathrm{KOH}:: 3: 1$ and $\mathrm{NaOH}: \mathrm{KOH}:: 1: 3$ to improve surface quality and increase machining depth during micro-channelling on silica glass by micro-ECDM process.

\section{Developed M-ecdm Set Up}

To commence the objectives of this research work and to control the process parameters micro-ECDM set-up was designed and developed in the laboratory. Micro-ECDM has three main sub- systems which are mechanical hardware system, electrolyte supply system and electrical power supply unit. Figure1 shows the developed $\mu$-ECDM system.

\section{Experimental Planning}

To investigate the influences of process variables like voltage, concentration of electrolyte(wt\%), duty ratio(\%), pulse frequency $(\mathrm{Hz})$ etc on machining depth $(\mathrm{MD})$ and surface roughness $(\mathrm{SR})\left(\mathrm{R}_{\mathrm{a}}\right)$ using with the help of spring feed mechanism by using a cylindrical shaped stainless steel tool of diameter 200 $\mu \mathrm{m}$ and mixture electrolyte solution of $\mathrm{NaOH}$ and $\mathrm{KOH}$ at the ratio of 1:0, 0:1, ,1:1, 3:1 and 1:3 ratio are used for experimentation. Voltage (35-55v), electrolyte concentration(10-30wt\%), pulse frequency (200-1000 $\mathrm{Hz}$ ) and duty ratio (45-65\%), inter-electrode gap (IEG) $40 \mathrm{~mm}$ and stand-off distance $0.5 \mathrm{~mm}$ have been well thought-out during micro-channelling operation on glass. For better quality of micro-channel surface as well as to reduce side sparking, new micro-tool is used for each experiment during ECDM process.

\subsection{EXPERIMENTAL RESULTS AND DISCUSSION}

Each experiment was conducted three times at every set of machining parametric combination and graphical plots are done individual input-output steps for analysis of effects and comparative study of mixed electrolyte at different proportion.

\subsubsection{Influences of Process Parameters and Comparative Studies of Machining Depth (MD)}


The comparison of the machining depth (MD) using five different electrolytes $\mathrm{NaOH}: \mathrm{KOH}::$ 1:0, $\mathrm{NaOH}: \mathrm{KOH}:: 0: 1$ and mixture of $\mathrm{NaOH}: \mathrm{KOH}:: 1: 1, \mathrm{NaOH}: \mathrm{KOH}:: 3: 1$ and $\mathrm{NaOH}: \mathrm{KOH}:: 1: 3$ with varying concentrations and voltage change, duty ratio change and varying of pulse frequency has been shown in figures 2 (a) - (d). From the figure 2 (a) it is reported that $\mathrm{NaOH}: \mathrm{KOH}:: 3: 1$ provides the highest machining depth and $\mathrm{NaOH}: \mathrm{KOH}:: 1: 1$ gives lower machining depth respect to other type of electrolyte at any voltage. Machining depth become maximum at $50 \mathrm{~V}$ and after that machining depth decreases due to lack of electrolyte on the tool tip. From the figure 2(b) it is imaged that machining depth is lower at 10-15wt\% of $\mathrm{NaOH}: \mathrm{KOH}:: 1: 1$ and highest at 30 wt\% of $\mathrm{NaOH}: \mathrm{KOH}:: 1: 3$ when electrolyte concentration is varied from 10$30 \mathrm{wt} \%$. From the figure 2 (c) MD is higher at $60 \%$ of duty ratio for any type of electrolyte when duty ratio is varied and other parameters are fixed. It is clear that applied voltage as well as electrolyte concentration plays important rolls to increase machining depth because of rising of conductivity and sparking rate. From the figure 2(d) it is illustrated that machining depth become higher at lower pulse frequency and become higher when $\mathrm{NaOH}: \mathrm{KOH}:: 3: 1$ is used as electrolyte during varying pulse frequency, keeping other parameter constant at 35v/40\%/IEG 40mm and lower at $\mathrm{NaOH}: \mathrm{KOH}:: 1: 1$. Machining depth decreases when pulse frequency increases because current density decreases. As a result machining rate decreases, i.e. material removal decreases and machining depth decreases.

\subsubsection{Influences of Process Parameters and Comparative Studies on Surface Roughness $\left(R_{a}\right)$}

The comparison of the surface roughness (SR) using five different electrolytes $\mathrm{NaOH}: \mathrm{KOH}:: 1: 0$, $\mathrm{NaOH}: \mathrm{KOH}:: 0: 1$ and mixture of $\mathrm{NaOH}: \mathrm{KOH}:: 1: 1, \mathrm{NaOH}: \mathrm{KOH}:: 3: 1$ and $\mathrm{NaOH}: \mathrm{KOH}:: 1: 3$ with varying concentrations and voltage change, duty ratio change and varying of pulse frequency has been shown in figures 3 (a) - (d), when one parameter is varying, other parameters remaining fixed. It is found that surface finish of micro-channel is better when $\mathrm{NaOH}: \mathrm{KOH}:: 3: 1$ is used as electrolyte and surface roughness is augmented as increase of applied voltage at other parameters are unaltered, figure 3 (a) represents. At $35 \mathrm{~V}$ surface roughness is higher in case of $\mathrm{NaOH}: \mathrm{KOH}:: 1: 3$ and lower for $\mathrm{NaOH}: \mathrm{KOH}:: 3: 1$. As at $50 \mathrm{~V}$, continuous sparking occurs that causes better surface finish in to the channel. Therefore the surface smoothness deteriorates due to thermal effects when $\mathrm{NaOH}: \mathrm{KOH}:: 0: 1$ is used at higher voltage and becomes more at $55 \mathrm{~V}$. From the figure $3(\mathrm{~b})$ it is observed that $\mathrm{NaOH}: \mathrm{KOH}:: 3: 1$ provides lower surface roughness and $\mathrm{NaOH}: \mathrm{KOH}:: 1: 3$ gives continuous surface finish when electrolyte concentration is increased up to $25 \mathrm{wt} \%$ and surface texture become greater when $\mathrm{NaOH}: \mathrm{KOH}:: 0: 1$ is used as electrolyte with $30 \mathrm{wt} \%$ concentration. From the figure 3 (c) it can obviously announced that surface smoothness is decreased when duty ratio is increased, due to higher sparking thermal damage occurred and irregularities in to the micro-channel increases. At 55\% duty ratio/10wt\%/200 Hz/IEG 40mm surface finish is better in case of all types of electrolyte and at $45 \%$ duty ratio surface roughness is lower for $\mathrm{NaOH}: \mathrm{KOH}:: 3: 1$ and higher at $65 \%$ duty ratio that causes violent sparking when $\mathrm{NaOH}: \mathrm{KOH}:: 0: 1$ is used. From the figure 3(d) it can be explained that surface roughness is continuous up to $600 \mathrm{~Hz}$ and after that increasing pulse frequency surface roughness become higher because of discontinuous discharge and side stray of sparking. It is clear that at $200 \mathrm{~Hz}$ surface roughness is lower when $\mathrm{NaOH}: \mathrm{KOH}:: 3: 1$ is used as electrolyte and higher at $1 \mathrm{KHz}$ in case of $\mathrm{NaOH}: \mathrm{KOH}:: 0: 1 . \mathrm{NaOH}: \mathrm{KOH}:: 3: 1$ is better electrolyte for better 
surface finish of silica glass micro-channel. Figure 4 show the graphical plot of roughness $\left(R_{a}\right)$ of the surface of micro-channel fabricated on silica glass, machined at different parametric combination like 50V/25wt\%NaOH:KOH:: 1:0/55\%/600Hz, 35V/15wt\%NaOH:KOH::3:1/50\%/600Hz and $50 \mathrm{~V} / 15 \mathrm{wt} \% \mathrm{NaOH}: \mathrm{KOH}:: 1: 350 \% / 400 \mathrm{~Hz}$.

\subsection{Comparative Studies on Machining Depth (MD), Surface Roughness $\left(R_{a}\right)$ and Tool Electrode Wear Rate (TEWR) Using Different Electrolyte and Polarity}

Total fifteen experiments have been conducted with different polarities for five different electrolytes mixtures i.e., $\mathrm{NaOH}$ and $\mathrm{KOH}$ are mixed at the ratio of 1:0, 3:1, 1:1, 1:3 and 0:1, by fixing the electrolyte concentration at $10 \mathrm{wt} \%$ and other process parameters viz. applied voltage, type of electrolyte; pulse frequency, inter-electrode gap and duty ratio. Figures $5(\mathrm{a})$ and (b) show the schematic diagrams of direct polarity and reverse polarity of micro-tool in $\mu$-ECDM process.

\subsubsection{Effect of Polarity on Machining Depth (MD)}

In the present work, the machining depth has been compared for both polarities i.e. direct and reverse in five different mixtures of electrolyte solutions and exhibits in figure 6 . The figure 6 clearly indicates that in case of reversed polarity the machining depth is obtained low because machining rate is low due to low sparking rate. It is found that for reversed polarity as well as direct polarity the $50-50 \%$ mixture of electrolytes provides lower machining depth whereas 3:1 ratio of $\mathrm{NaOH}$ and $\mathrm{KOH}$ electrolyte mixtures provides higher machining depth (MD) during micro-channel fabrication on silica glass. The discrepancy of machining depth is found as usual for both polarities in five different mixtures.

\subsubsection{Effect of Polarity on Surface Roughness $\left(R_{a}\right)$}

Figure 7 exhibits the effects of polarities of D.C. power supply on surface roughness for different mixtures of electrolyte. It can also be notice from the figure8 that good surface finish can be achieved by using direct polarity rather than reverse polarity. In direct polarity uniform sparking rate is high whereas in revered polarity uniform sparking rate is comparatively low. There is a tendency to stray around the cutting zone; as a result irregularities are formed on the machining zone and the value of surface roughness becomes higher. From this observation it can be predicted that direct polarity is better than reverse polarity in case of surface texture of machined zone of the job specimen. From the figure 7 it is found that at $10 \mathrm{wt} \%$ of electrolyte mixture at the ratio 0:1 solution gives more irregular surface and causes higher surface roughness at reversed polarity whereas the ratio of 3:1 provides lower surface roughness in case of reverse polarity. For direct polaritythe ratio of 1:3 of $\mathrm{NaOH}$ and $\mathrm{KOH}$ provides higher surface roughness comparatively to other types and lower for the ratio of 3:1.

\subsubsection{Effect of Polarity on Tool Electrode Wear Rate (TEWR)}

Tool electrode wear rate has been compared for both polarities i.e. direct and reverse in five different types of electrolyte mixture i.e., $\mathrm{NaOH}$ and $\mathrm{KOH}$ are mixed at the ratio of 1:0, 3:1, 1:1, 1:3 and 0:1 and are 
shown in figure 8. It is observed from figure 8 that more tool electrode wear rate is occurred in case of direct polarity compared to the reverse polarity. In direct polarity sparking rate is high compared to that in revered polarity and higher temperature raises in the cutting zone, as a results more tool wear is occurred in case of direct or straight polarity. From the figure 8 it is found that more tool wear rate is occurred due to higher rate of sparking at direct polarity with $10 \mathrm{wt} \%$ of $0: 1$ ratio of $\mathrm{NaOH}$ and $\mathrm{KOH}$ electrolyte mixture and 1:3 ratio provides lower tool wear rate for both direct and reverse polarity. The tool wear rate initially starts at $45 \mathrm{~V}$ for stainless steel micro-tool for direct as well as reverse polarity during micro-machining by ECDM process. Tool wear rate is found low in case of mixed electrolyte compared to $\mathrm{NaOH}$ and $\mathrm{KOH}$ electrolyte. But increasing of material removal rate is the main target, so direct polarity is the best polarity for the micro-fabrication of silica glass. SEM images of micro-channel of silica glass are exhibited in figure 9 using various electrolyte solutions and at different machining conditions.

\section{Conclusions}

From the present parametric analysis and comparative study using different electrolyte and tool polarity change during $\mu$-channel cutting operation on silica glass by advanced micro-ECDM process, the present set of research following outcome drawn out-

i. Electrochemical discharge micro-machining (ECDM) system successfully design, fabricated and developed for different shapes of $\mu$-channel as well as micro-profile cutting on electrically nonconducting material like silica glass.

ii. Machining depth as well as surface roughness increases by escalating of voltage, duty ratio and electrolyte concentration but after $55 \mathrm{~V}$ and $60 \%$ of duty ratio machining depth decreases. Pulse frequency is inversely proportionate with machining depth and achieved better machining depth at $600 \mathrm{~Hz}$ but less effect on surface roughness.

iii. At $50 \mathrm{~V}$ and $25 \mathrm{wt} \%$ sparking is continuous, so enhanced surface finish can be found and $400-600 \mathrm{~Hz}$ pulse frequency.

iv. Surface becomes rough due to the thermal effects in the machining zone when $\mathrm{NaOH}: \mathrm{KOH}:: 0: 1$ is used at 55 volt and $30 \mathrm{wt} \%$. $\mathrm{NaOH}: \mathrm{KOH}:: 3: 1$ provides lower surface roughness

and $\mathrm{NaOH}: \mathrm{KOH}:: 1: 3 g$ gives continuous surface finish when electrolyte concentration is increased up to $25 \mathrm{wt} \%$.

$\mathrm{v}$. It is found that more tool wear rate occurred due to higher rate of sparking at direct polarity with 10 wt\% of $\mathrm{NaOH}: \mathrm{KOH}:: 0: 01$ electrolyte solution and $\mathrm{NaOH}: \mathrm{KOH}:: 1: 3$ provides lower tool wear rate at reverse polarity and if tool wear occurs, surface roughness raises.

vi. ' $Y$ ' shape, 'Zig-Zag' shape as well as 'micro-slot' has been cut at $50 \mathrm{~V} / 10 \mathrm{wt} \% \mathrm{NaOH}: \mathrm{KOH}:: 3: 1$ $200 \mathrm{~Hz} / 45 \%$ with machining depth of $1850 \mu \mathrm{m}$ on silica glass.

vii. It is observed from Scanning Electron Microscopy (SEM) images that surface texture of $\mu$-channel on glass varies with different process parameters and micro-crack are observed in direct as well as reverse polarity. But more micro-crack is formed for reverse polarity. From SEM analysis of microchannel little debris are found and thermal effect is clearly observed. 


\section{Declarations}

\section{Funding statement: (Not applicable)}

This research work is fully self-financed and is not funded by any of the government/semi government/private organizations.

\section{Conflict of interest: (Not applicable)}

The authors have no conflicts of interest that may have a direct bearing on the subject matter of the article and it will not directly reflect any possible bias in either the exposition or the conclusions presented.

\section{Author contribution:}

All the authors have equal contribution in experimentation, results analysis and writing of manuscript.

\section{Availability of data and material:}

All the data used for analyzing the results of the current study are on hand with researchers and would be provided if necessary to the journal.

\section{Compliance with ethical standards: (Not applicable)}

This article does not contain any studies with human participants or animals performed by any of the authors.

\section{Consent to participate:}

The authors are free to get in touch with any of the people occupied in the research to seek further clearing up and information. We appreciate that under freedom of information legalization and entitled to right to use the information provided at any time while it is in storage as particular in the manuscript.

\section{Consent for Publication:}

The authors furnish their approval for the publication of specialized details, which can consist of photograph(s) and/or details within the manuscript to be in print in Silicon Journal.

\section{Acknowledgments:}

The authors are thankful to Global Institute of Management and Technology, Krishnanagar, WB and Jadavpur University, Production Engineering Department, Kolkata-32, India for giving the opportunity to carry out the total experimentation and analysis of the work.

\section{References}


[1] Basak, I.; Ghosh, A, "Mechanism of spark generation during electrochemical discharge machining: a theoretical model and experimental verification", Journal of MaterialsProcessing Technology, 62, 4653, DOI:10.1016/0924-0136(95)02202-3, 1996.

[2] Bhattacharyya, B.; Doloi, B.; Sorkhel, S.K, "Experimental investigations into electrochemical discharge machining (ECDM) of non-conductive ceramic materials", Journal of Materials Processing Technology, 95, 145-154, DOI:10.1016/S0924-0136(99)00318-0, 1999.

[3] Wüthrich, R.; Fascio, V, "Machining of non-conducting materials using electrochemical discharge phenomenon-an overview", International Journal of Machine Tools \& Manufacture, 45(9), 1095-1108, DOI: 10.1016/j.ijmachtools.2004.11.011, 2005.

[4] Sarkar, B.R.; Doloi, B.; Bhattacharyya, B, "Parametric analysis on electrochemical discharge machining of silicon nitride ceramic", International Journal Advanced Manufacturing Technology, 28(9), 873-881, DOI: 10.1007/s00170-004-2448-1, 2006.

[5] Kim, D.J., Ahn, Y., Lee, S.H. and Kim, Y.K, "Voltage pulse frequency and duty ratio effects in an electrochemical discharge micro-drilling process of Pyrex glass", International Journal of Machine Tools \& Manufacture, 46, 1064-1067, DOI:10.1016/j.ijmachtools.2005.08.011, 2006.

[6] Yan, B. H., Yang, C. T., Huang, F. Y. and Lu, Z. H, “Electrophoretic deposition grinding (EPDG) for improving the precision of microholes drilled via ECDM", Journal of Micromechanics \& Microengineering, 17, 376-383,DOl:https://doi.org/10.1088/0960-1317/17/2/025, 2007.

[7] Sarkar B.R.; Doloi B.; Bhattacharyya B,"Experimental investigation into electrochemical discharge micro drilling on advanced ceramics", InternationalJournal of Manufacturing Technology and Management, 13(2/3/4), 214 - 225, DOI: 10.1504/IJMTM.2008.016772, 2008.

[8] Sarkar B.R.; Doloi B.; Bhattacharyya B,"Investigation into the influences of the power circuit on the micro-electrochemical discharge machining process", Proceedings of the Institution of Mechanical Engineers, Part B: Journal of Engineering Manufacture, 223 (2), 133 144,DOI:10.1243/09544054JEM1258, 2009.

[9] Han, M. S.; Min, B. K; Lee, S. J,“Geometric improvement of electrochemical discharge micro-drilling using an ultrasonic-vibrated electrolyte", Journal of Micromechanics \& Micro engineering, 19, 065004 (8pp),DOI:10.1088/09601317/19/6/065004, 2009.

[10] Cheng, C. P., Wu, K. L., Mai, C. C., Hsu, Y. S. and Yan, B. H., "Magnetic field-assisted electrochemical discharge machining", Journal of Micromechanics \&Microengineering,20, 075019 (7pp)DOI: 10.1088/0960-1317/20/7/075019, 2010.

[11] Liu, J. W., Yue, T. M., Guo, Z. N,“'An analysis of the discharge mechanism in electro chemical discharge machining of particulate reinforced metal matrix composites", International Journal of Machine 
Tools \& Manufacture, 50, 86-96,DOI: 10.1016/j.ijmachtools.2009.09.004, 2010.

[12] Yang, C.-K., Cheng, C.-P., Mai, C.-C., Wang, A. C., Hung, J.-C., Yan, B.-H, "Effect of surface roughness of tool electrode materials in ECDM performance", International Journal of Machine Tools \& Manufacture, 50, 088-1096 DOI: 10.1016=j.ijmachtools.2010.08.006, 2010.

[13] Cheng C. P., Wu, K. L, Mai, C. C., Yang, C. K., Hsu, Y. S., Yan, B. H, "Study of gas film quality in electrochemical discharge machining", International Journal of Machine Tools \& Manufacture, 50, 689-697,DOI: 10.1016/j.jjmachtools.2010.04.012, 2010.

[14] Cao, X. D., Kim, B. Y. and Chu, C. N,“'Hybrid Micromachining of Glass using ECDM and Micro Grinding", International Journal of Precision Engineering and Manufacturing, 14 (1), 5-10, DOI: 10.1007/s12541-013-0001-6, 2013.

[15] Gupta, P.K.:Dvivedi, A.; Kumar, P,“Effect of Pulse Duration on Quality Characteristics of Blind Hole Drilled in Glass by ECDM", Materials and Manufacturing Processes, 0: 1-9. DOI:

10.1080/10426914.2015.1103857, 2016.

[16] Hajian, M.; Razfar, M.R.; Movahed, S."An experimental study on the effect of magnetic field orientations and electrolyte concentrations on ECDM milling performance of glass", Precision Engg., 45, 322-331, DOI: 10.1016/j.precisioneng.2016.01.007, 2016.

[17]Saranya, S.; Nair, A.; Ravi Sankar, A., "Experimental investigations on the electrical and 2D-machining characteristics of an electrochemical discharge machining (ECDM) process", Microsystem Technologies, 22, 1-9, DOI 10.1007/s00542-016-3027-8, 2016.

[18] A. Behroozfar and M. R. Razfar,“Experimental Study of the Tool Wear During the Electrochemical Discharge Machining" Materials and Manufacturing Processes, 31: 574-580, DOI:

10.1080/10426914.2015.1004685, 2016.

[19] B. Mallick; B.R. Sarkar; B. Doloi; B. Bhattacharyya, "Analysis on Electrochemical Discharge Machining during Micro-channel Cutting on Glass" Int. J. of Precision Technology, 7, 1, 32-

50,DOI: http://dx.doi.org/10.1504/IJPTECH.2017.10005511, 2017.

[20] J. Bindu Madhavi, Somashekhar S. Hiremath, "Machining and Characterization of Channels and Textures on Quartz Glass Using $\mu$-ECDM Process", S.S. Silicon,1-13,DOl:http://dx.doi.org/10.1007/s12633019-0083-6, 2019.

[21] Bellubbi, S., N, S. \& Mallick, B, "Multi Response Optimization of ECDM Process Parameters for Machining of Micro channel in Silica Glass Using Taguchi-GRA Technique". Silicon (2021). https://doi.org/10.1007/s12633-021-01167-4, 2021. 


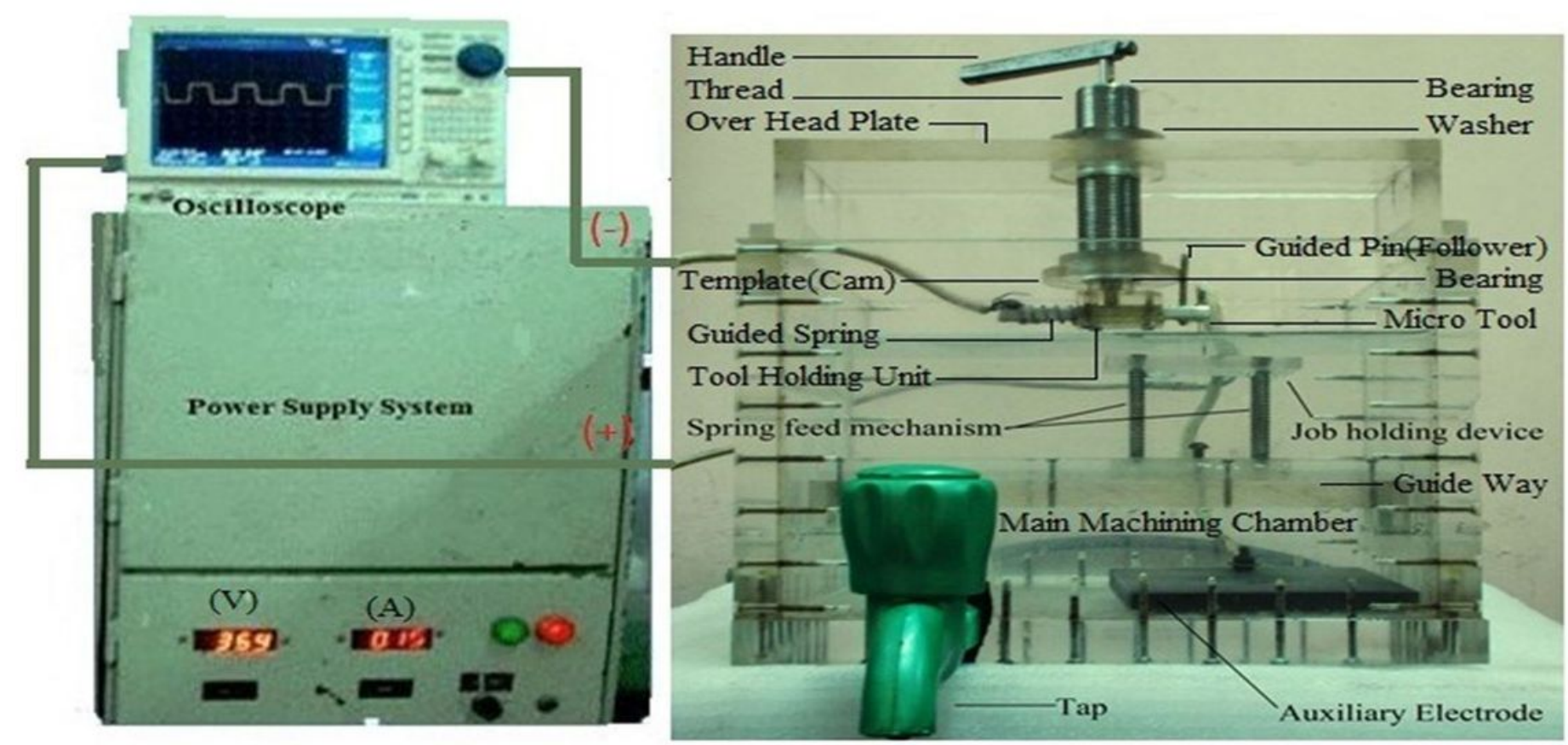

Figure 1

Diagram of $\mu$-ECDM Experimental set-up 


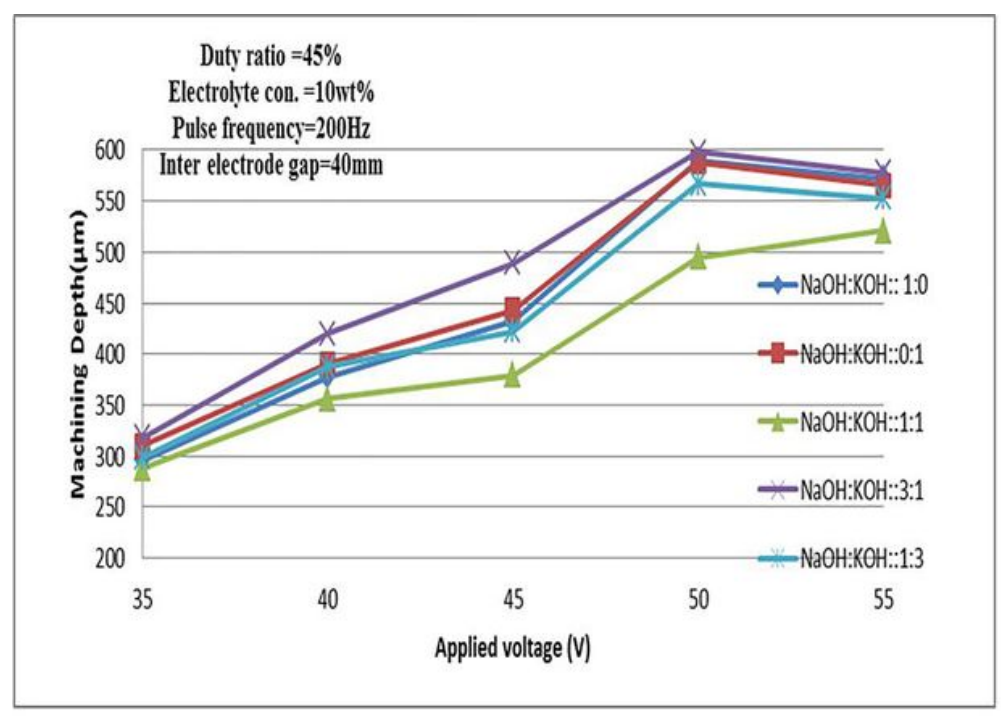

(a)Effect of applied voltage on MD

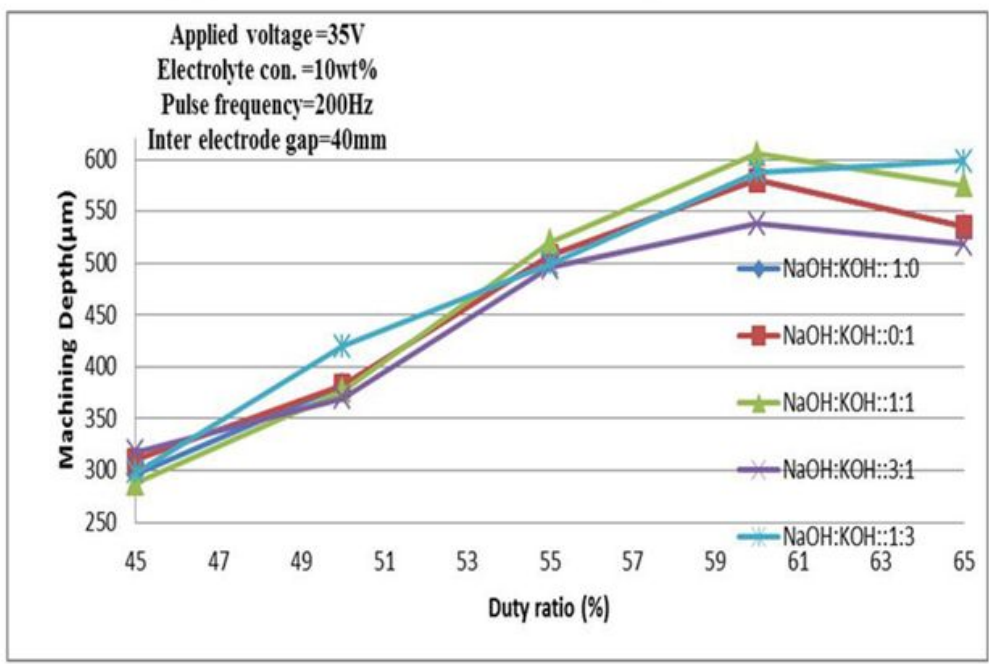

(c) Effect of duty ratio on MD

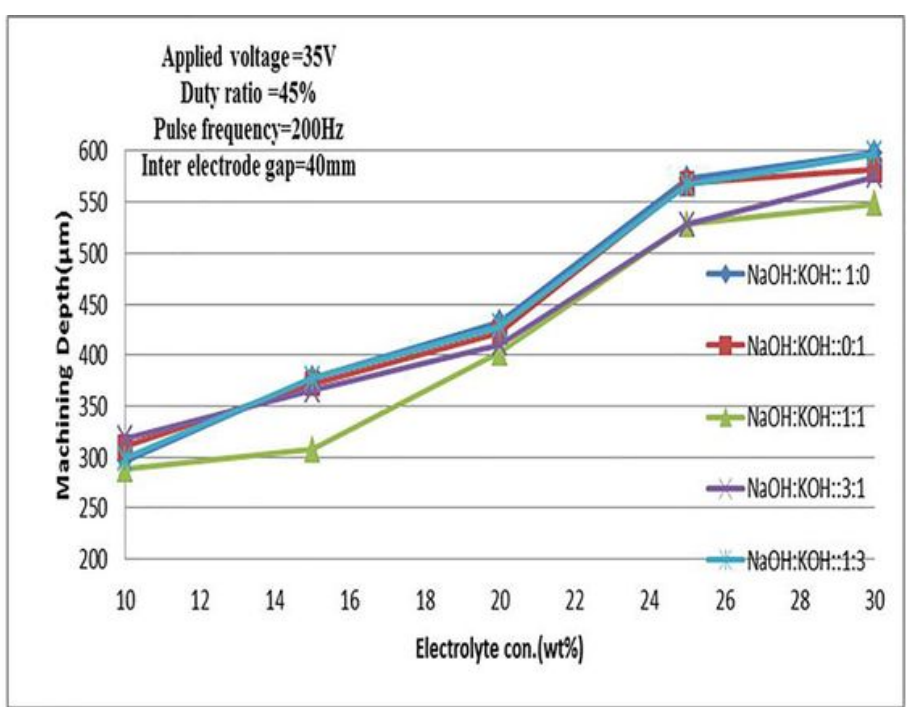

(b) Effect of electrolyte concentration on $\mathrm{MD}$

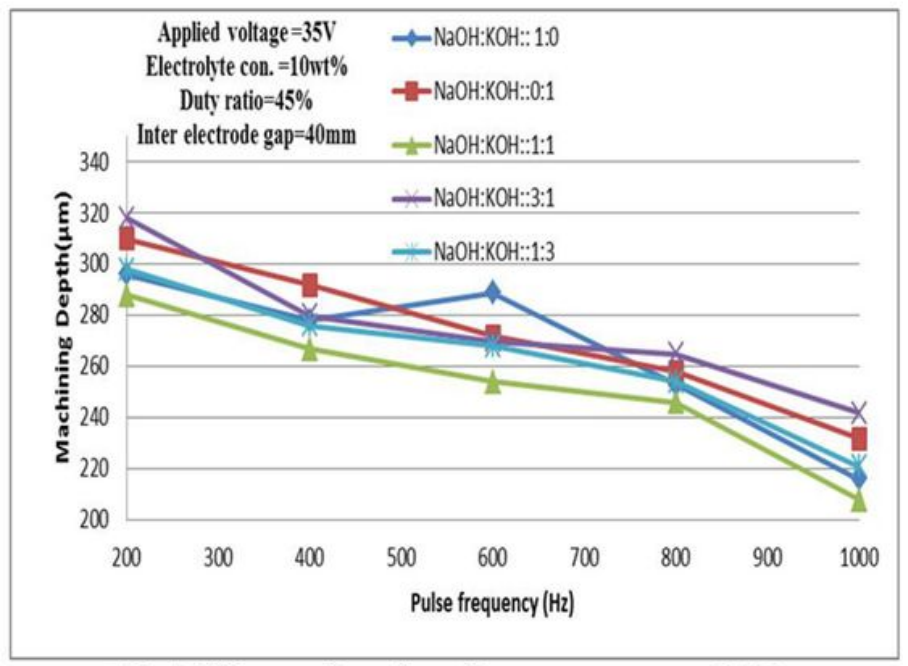

(d) Effect of pulse frequency on MD

Figure 2

(a)-(d) Comparative study of machining depth using mixed electrolyte 

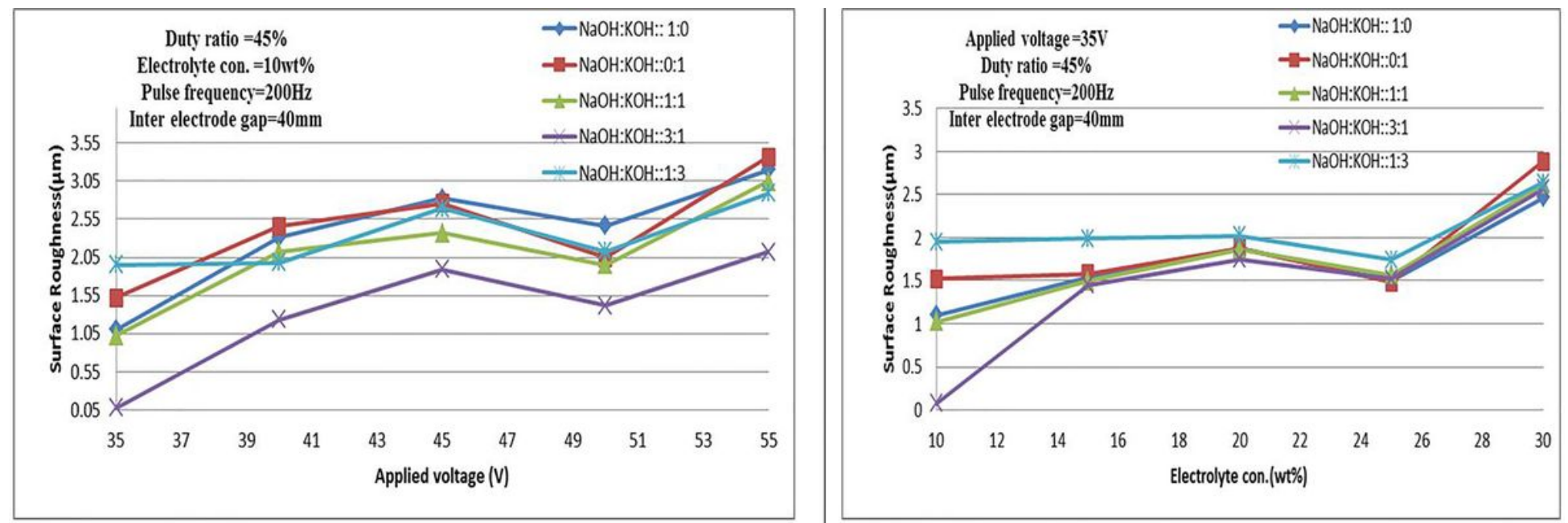

(b) Effect of electrolyte concentration on $\mathrm{R}_{\mathrm{a}}$

(a) Effect of applied voltage on $\mathrm{R}_{\mathrm{a}}$

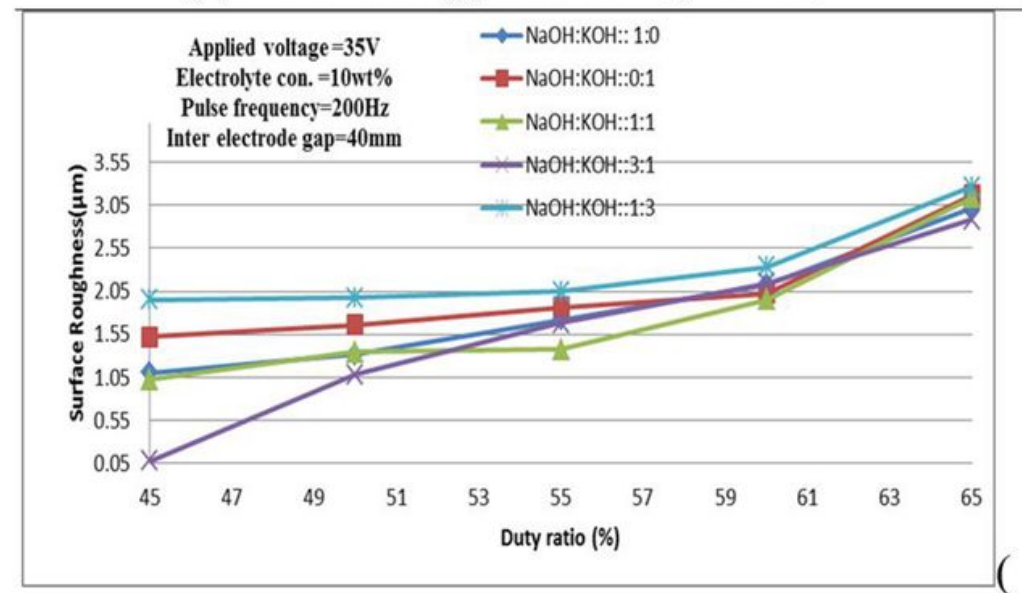

c) Effect of duty ratio on $R_{a}$

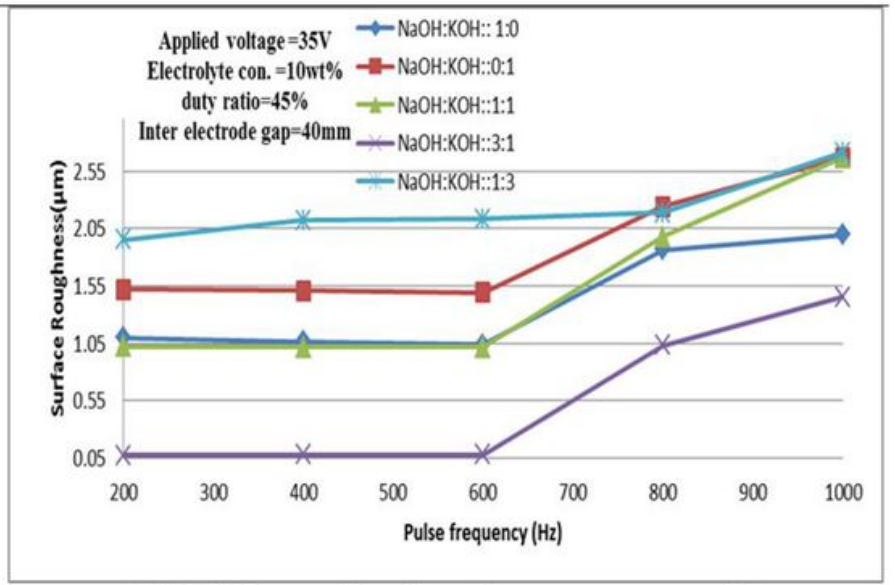

(d) Effect of pulse frequency on $R_{a}$

\section{Figure 3}

(a) - (d) Comparative study of surface roughness using mixed electrolyte 


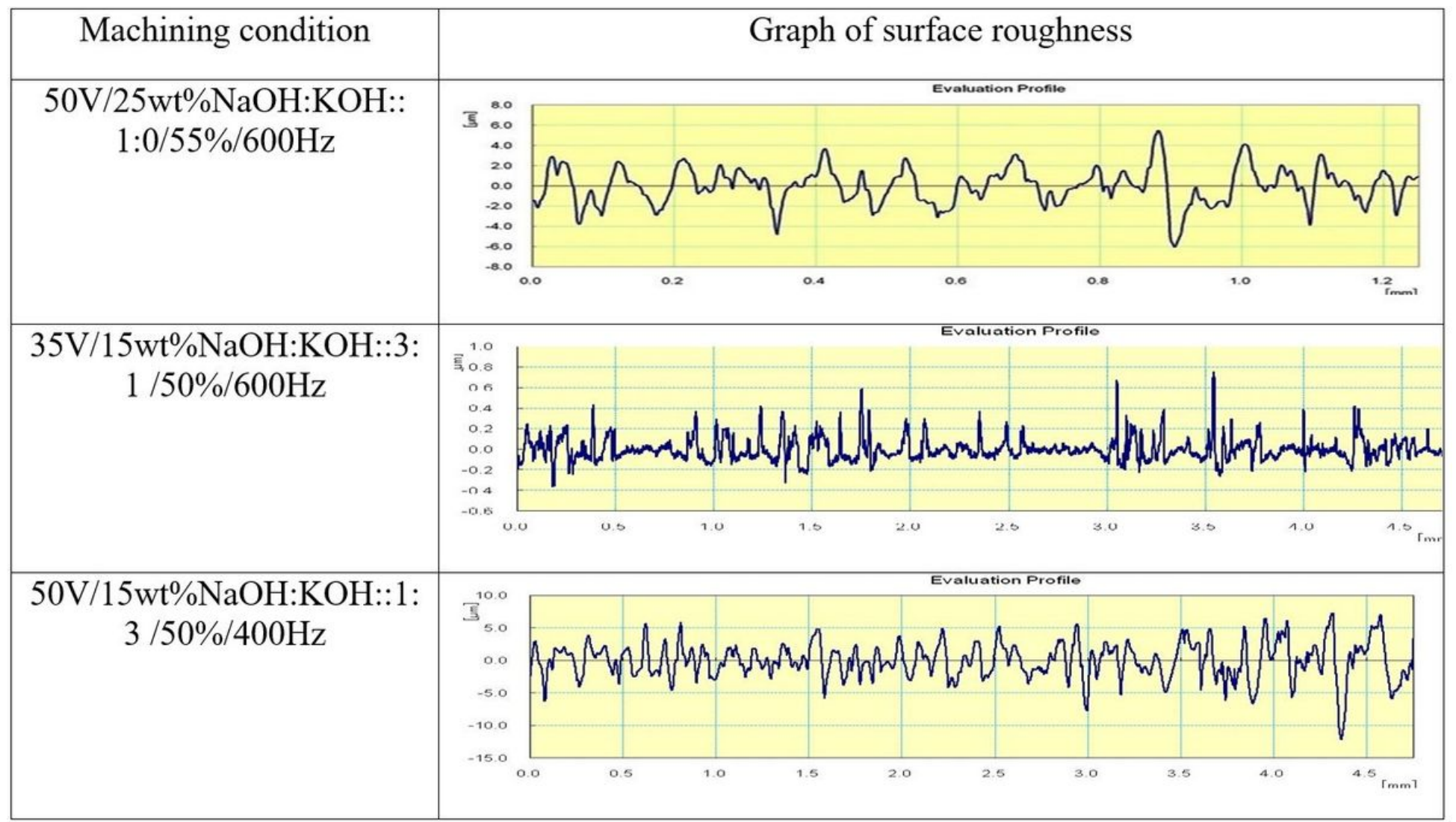

Figure 4

Surface texture of micro-channel on glass at different conditions

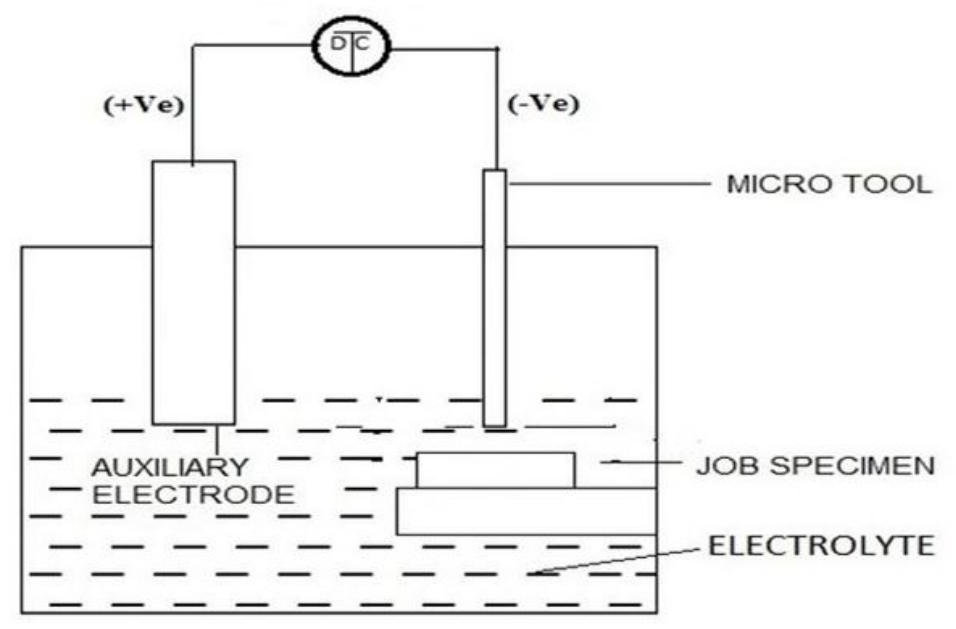

(a) Direct polarity

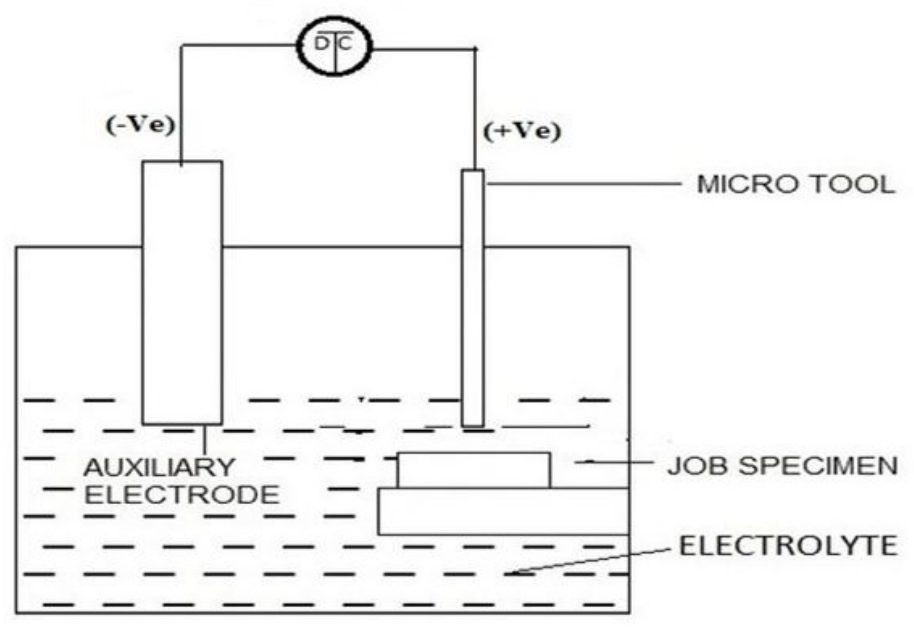

(b) Reverse polarity

Figure 5

Schematic diagrams of (a) direct polarity and (b) reverse polarity of $\mu$-tool of $\mu$-ECDM. 


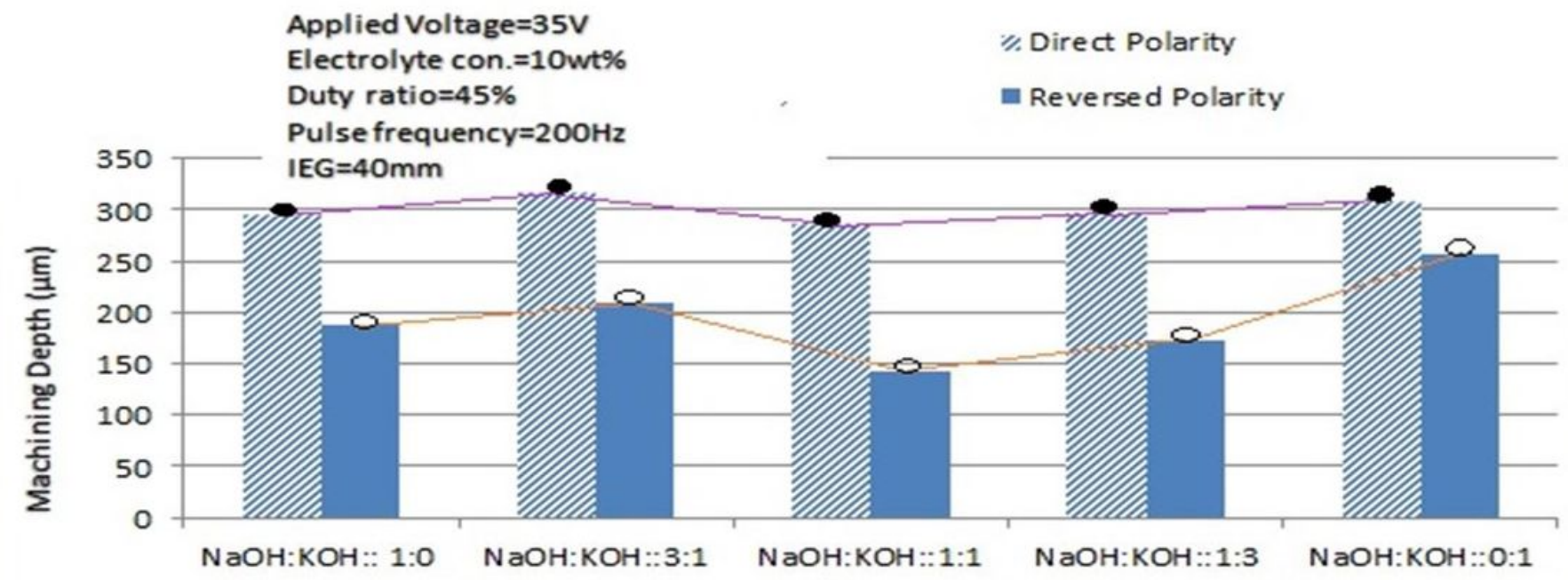

Figure 6

Effect of polarities on Machining Depth

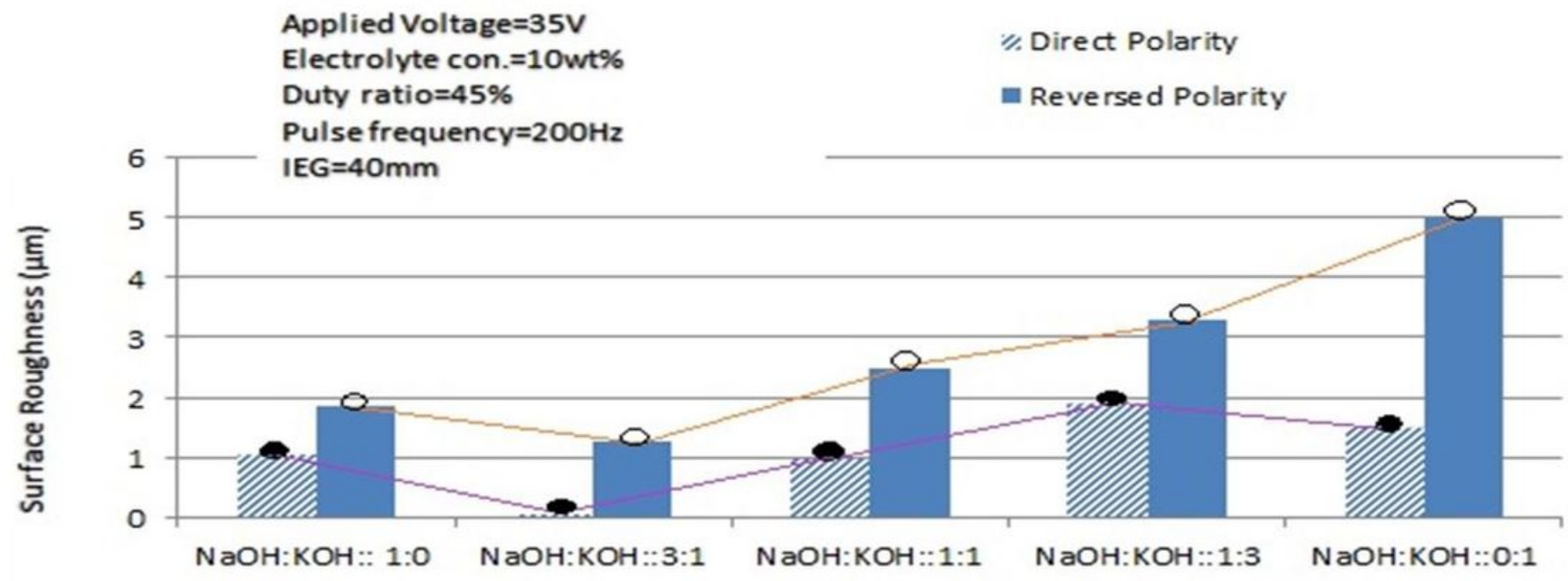

Figure 7

Effect of polarities on Surface Roughness 


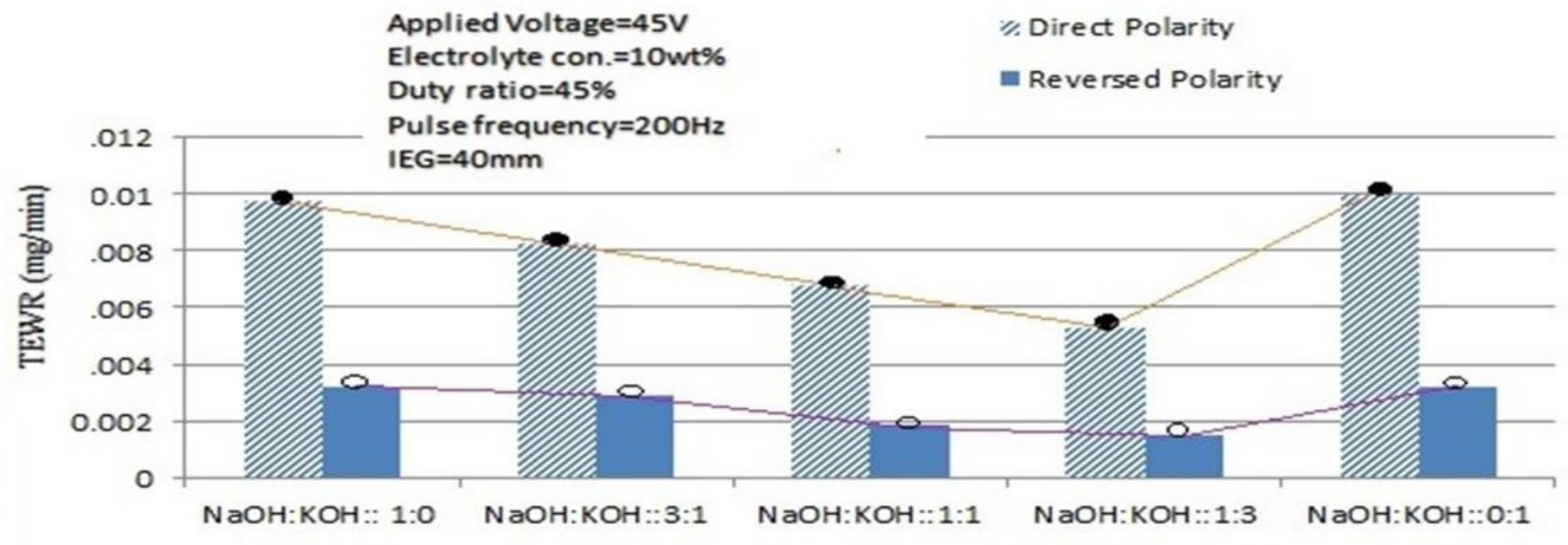

Figure 8

Effect of polarities on Tool Electrode Wear Rate (TEWR)

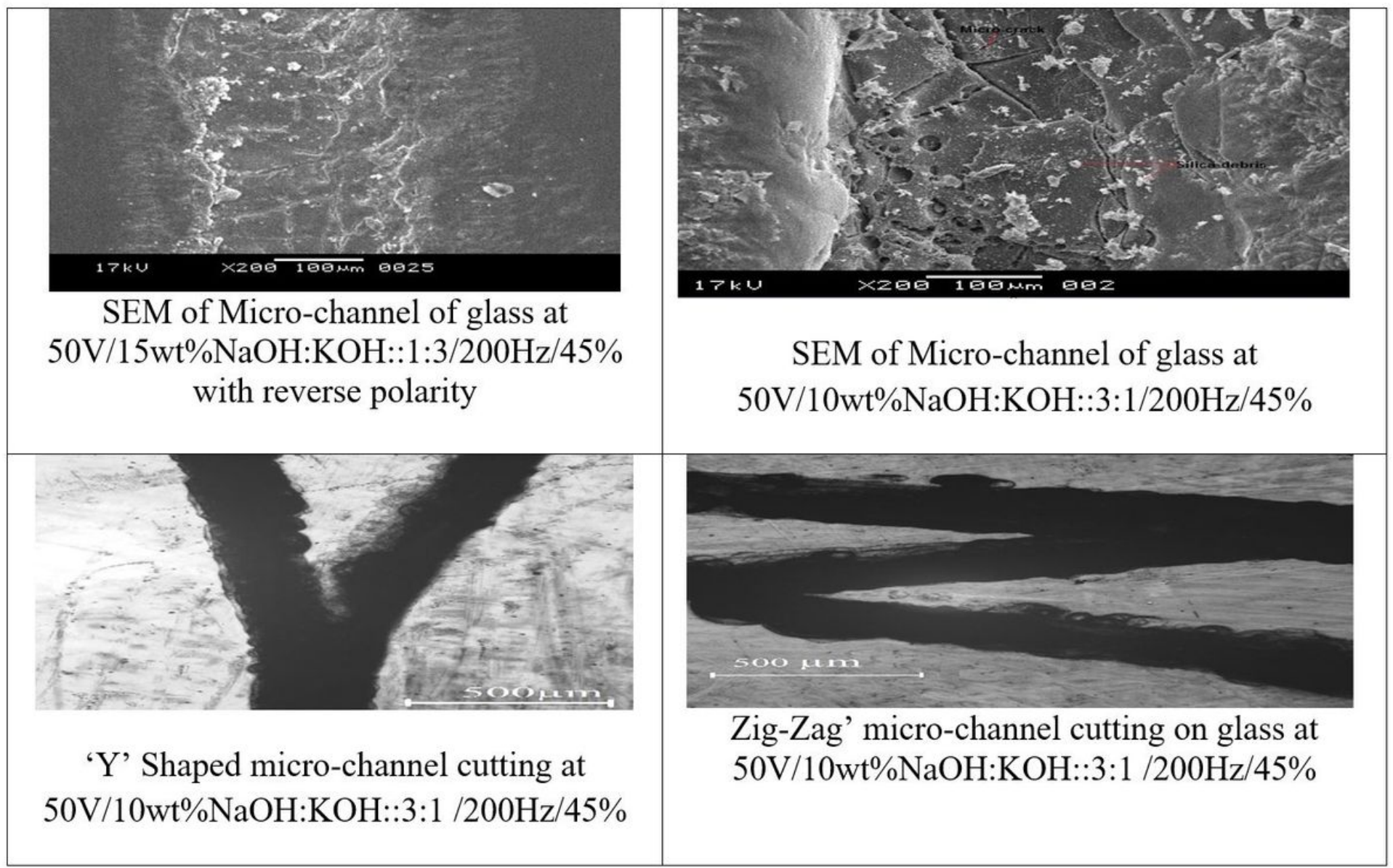

\section{Figure 9}

Different shapes of micro-channels cutting at different conditions on glass by $\mu$-ECDM process 